\title{
Operation Mode Transition of a Low-Voltage Single Phase Microgrid based on Synchronization Controller
}

\author{
Qusay Salem ${ }^{1}$, Khaled Alzaareer ${ }^{2}$ and Salman Harasis ${ }^{3}$ \\ ${ }^{1}$ Department of Electrical Engineering, Princess Sumaya University for Technology (PSUT), \\ Amman, Jordan \\ ${ }^{2}$ Department of Electrical Engineering, Quebec University, Montreal Québec, Canada \\ ${ }^{3}$ Department of Electrical Engineering, Tafila Technical University, Tafila, Jordan. \\ ${ }^{1}$ q.salem@psut.edu.jo, ${ }^{2}$ khaled.alzaareer.1@ens.etsmtl.ca, ${ }^{3}$ salmanharasis@ttu.edu.jo
}

\begin{abstract}
In case of system contingencies, improving the continuity of the electrical supply by islanding capabilities is of great interest. Besides, reconnecting the power network after an islanding event is also an important issue for maintaining the power system stability. This paper investigates the disconnection and reconnection of a microgrid consisting of two DG voltage source inverters in case of a grid disturbance. The main problem is to achieve a smooth transition between both modes of operation by implementing proper control strategies for the DGs and incorporating a robust synchronization controller. The synchronization controller is implemented to synchronize the microgrid with the main grid after an unintentional islanding condition. Flip flops are utilized to manage the set and reset operation of the static switch and the DG VSI operation mode depending on the network status. The system performance under the short circuit condition has been validated through simulations using SimPowerSystems toolbox in Matlab/Simulink software.
\end{abstract}

Keywords: Microgrid; Grid connected mode; Islanded mode; Synchronization controller; Grid disturbance.

\section{Introduction}

Due to the immense penetration of the renewable energy sources, the development of distributed generator power converters integrated to the low voltage network has rapidly increased [1, 2, 3, 4]. The microgrid in general, consists of three main elements which are: distributed generators, controllable loads, and storage elements. It has the ability to operate islandly or interconnected to the main network either a low or medium voltage network $[5,6,7]$. The transition between both modes of operation should be smooth in order to avoid deleterious overcurrent transients. Therefore, the voltage magnitude, frequency and phase angle of both networks should be matched to achieve this target. In other words, the difference between these quantities for the main grid and the microgrid should be as small as possible before the reconnection process. In the event of grid disturbances, unstable power conditions may emerge because of the microgrid disconnection from the main grid. However, these instabilities should be eliminated at the instant of reconnection if both networks are successfully synchronized $[8,9$, $10]$.

The synchronization problem has been discussed by many researchers lately. Most of the papers focuses on two major objectives: the first one is fault ride-through capability to limit the fault current so that the microgrid can still work in grid connected mode or the implementation of fast grid voltage synchronization algorithms using sophisticated schemes. Many techniques have been investigated to achieve the requirements of the fault ride-through either for individual distributed generators or at the point of common coupling between the microgrid and main grid to alleviate the disconnection probability. Reference [11] presents a fault ride through scheme using a mutual inductance placed at PCC to suppress the fault current and to maintain the microgrid grid-connected. The inductance requires no control but may misoperate for some fault locations or reverse power flow conditions. Enhancing the performance of the microgrid system and achieving smooth transition between its operation modes are proposed in [12] by installing

Received: July $2^{\text {nd }}, 2021$. Accepted: August $26^{\text {th }}, 2021$

DOI: 10.15676/ijeei.2021.13.3.4 
a superconducting fault current limiter (SFCL) at PCC between the main grid and the microgrid. Reference [13] investigates the microgrid fault ride through capability by installing a SFCL and implementing a relay protection coordination when a short circuit takes place inside the microgrid. Different fault cases have been proposed in [14] for a microgrid consisting of photovoltaic, wind generator and energy storage with the existence of a SFCL to relieve the short circuit current and recover the voltage sags. A control strategy for enhancing the microgrid ability to ride-through both balanced and unbalanced grid voltage sags is depicted in reference [15]. Fast fault detection techniques have been also intensively investigated to satisfy the microgrid synchronization with the main grid [16, 17]. Reference [18] presents two synchronization Phase-locked loops for synchronizing the microgrid with the main grid where one PLL is used to detect the microgrid phase voltage and the other for detecting the grid phase voltage. The quadrature grid voltage detection from a PLL for the sake of microgrid synchronization is presented in [19] and [20]. Detecting the phase and amplitude error in a $d q$ based reference frame using a single PLL for network synchronization have been investigated in [21] and [22]. Reference [23] presents a synchronization system based on a frequency locked loop in a stationary reference frame for phase angle detection. An active synchronizing control scheme which adopts a central based coordinated control for multiple DGs is presented in [24]. Also, a dual second order generalized integrator based on a frequency locked loop is presented in [25]. A transfer strategy based on droop control of local microsources is presented in [26] where the algorithm satisfies frequency synchronization and then phase synchronization regardless of the voltage magnitude coincidence.

In this paper, a synchronization controller is implemented within the islanded control unit of the microgrid to achieve seamless reconnection of the DGs voltage source inverters. The proposed controller is flexible and reliable where it exchanges the needed information with the inverters of the DGs inside the microgrid instantaneously. The islanded control unit is used to ensure high quality voltage profile and to provide the needed power for the local loads. During a short circuit condition, the static switch will open and the control units of the DGs will switch to the islanded mode where a synchronization controller is triggered to synchronize the DGs inside the microgrid with the main grid before reclosing the static switch.

The remainder of the paper is organized into five sections. Following the introduction, single line diagram of the proposed system and the control structure of the DG inverter in gridconnected mode are presented in section 2 . The structure of the synchronization controller is investigated in section 3 . Section 4 presents the results of the simulations which are conducted via Simpowersystems toolbox in Simulink. Finally, section 5 presents the conclusion.

\section{Description of the proposed model}

A single-phase power system model which includes two VSIs, two resistive loads, both forming the microgrid structure is depicted in Figure1. No energy storage devices are involved. A static switch (STS) is placed to connect and disconnect the microgrid from the utility grid when needed. $\boldsymbol{R}_{\text {line }}, \boldsymbol{L}_{\text {ine }}$ are the resistance and inductance of the line which are resistive in nature as the microgrid is at the distribution level. $\boldsymbol{L}_{\mathbf{1}}, \boldsymbol{L}_{2}$ indicate the output inductance of the DGs voltage source inverters. $\boldsymbol{P}_{1}, \boldsymbol{Q}_{\mathbf{1}}$ and $\boldsymbol{P}_{\mathbf{2}}, \boldsymbol{Q}_{\mathbf{2}}$ are the real and reactive power generated by the two DGs voltage source inverters. Both distributed generators inject the required active power to their loads then the rest of power (denoted by $\boldsymbol{P}_{T}, \boldsymbol{Q}_{T}$ ) transfers to the utility grid.

Both DGs have identical control strategies in grid-connected mode. The voltage source inverters of the DGs were modelled as ideal controlled voltage sources. The control strategy for grid connected mode is shown in Figure 2 and investigated in [27, 28]. 


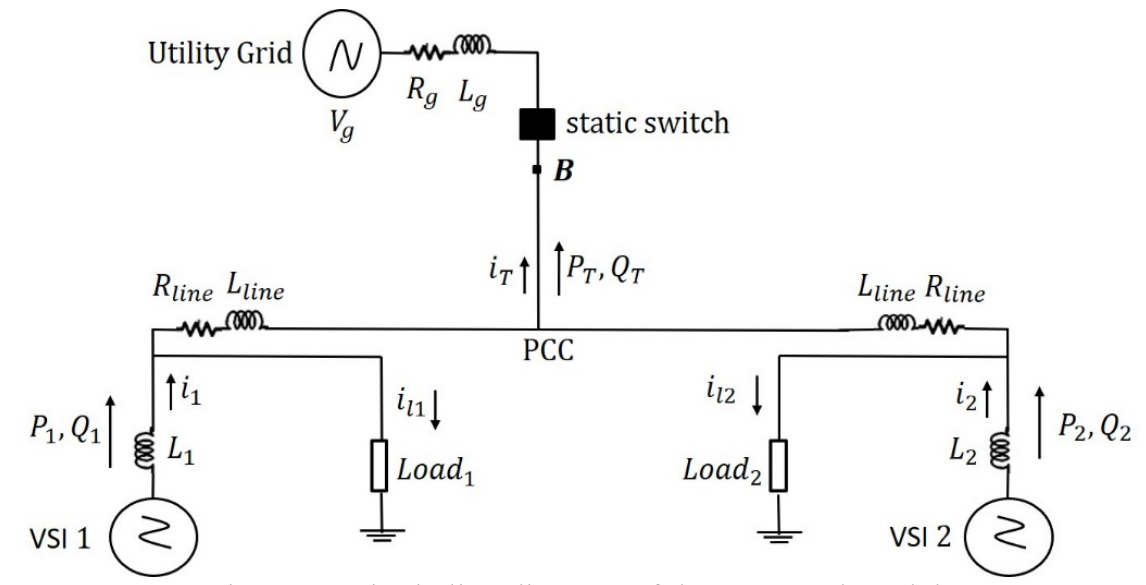

Figure 1. Single line diagram of the proposed model

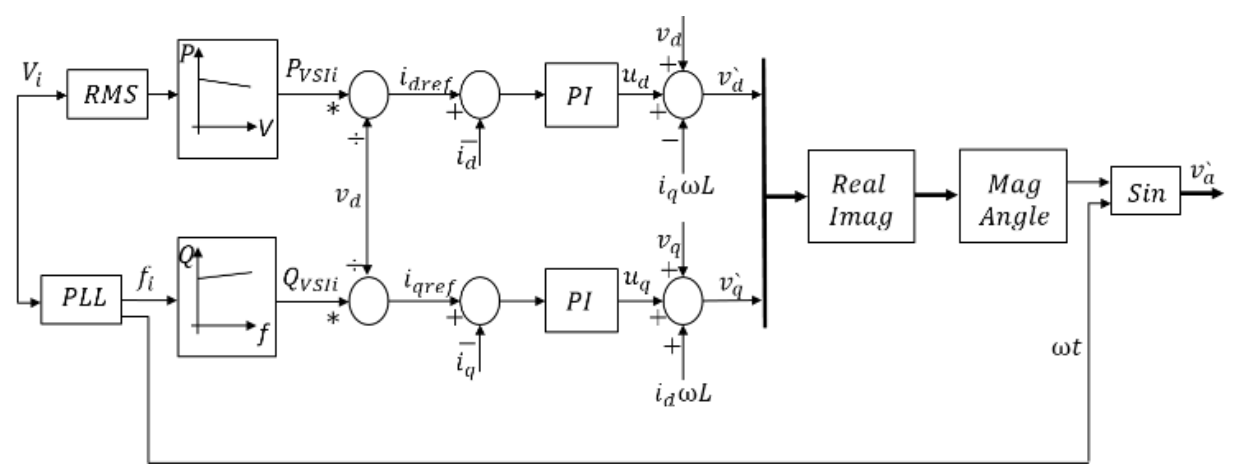

Figure 2. Control strategy of the single phase VSI in grid connected mode

\section{Structure of the synchronization controller}

When the DG is operating in the islanded mode, the reference voltage of the DG voltage source inverter is generated using an advanced control strategy. The control strategy employs a sinewave generator as an external dc source to generate the reference frequency and voltage magnitude for the DG operation when islanded. The operation mode of the voltage source inverter is changed from grid connected mode to islanded mode once a short circuit condition is revealed. However, the voltage source inverter of the DG should be coincided with the main grid before reconnection to avoid undesirable overcurrent transients [29, 30]. Therefore, during the islanded operation of the DG, the synchronization controller is triggered to minimize the voltage magnitude, frequency, and phase angle of the voltage source inverters to be matched with the main grid. As long as the microgrid is synchronized with the main grid, it is again reconnected and the control strategy of the voltage source inverters are changed from islanded mode to grid connected mode.

The structure of the synchronization controller which includes the control strategy of the voltage source inverter during islanded mode of the DG is presented in Figure 3. The voltage magnitude and frequency are generated from an external sinewave generator when the DG voltage source inverter works in islanded mode. The phase angle of the voltage source inverter extracted based on the sinewave generator $\theta_{\text {ext }}$ is chosen first. Then the new phase angle is chosen by the switch to synchronize the voltage source inverters of the DGs with the main grid. This new phase angle is nominated by $\theta_{\text {new }}$ which is derived once the synchronization controller is activated during the islanded mode. This is to make sure that the voltage source inverters of the DGs are synchronized with the utility grid. The synchronization criterion is accomplished by taking the phase difference between the utility grid voltage and the voltage source inverter 
voltage. Then, the sine of this angle difference went over a PI controller and compared with the old phase angle to extract the new phase angle of the DG. The sinewave of the new phase angle of each voltage source inverter is multiplied with the voltage magnitude to generate the reference sinewave voltage. This voltage is now passed through a voltage controller which is operated in island mode.

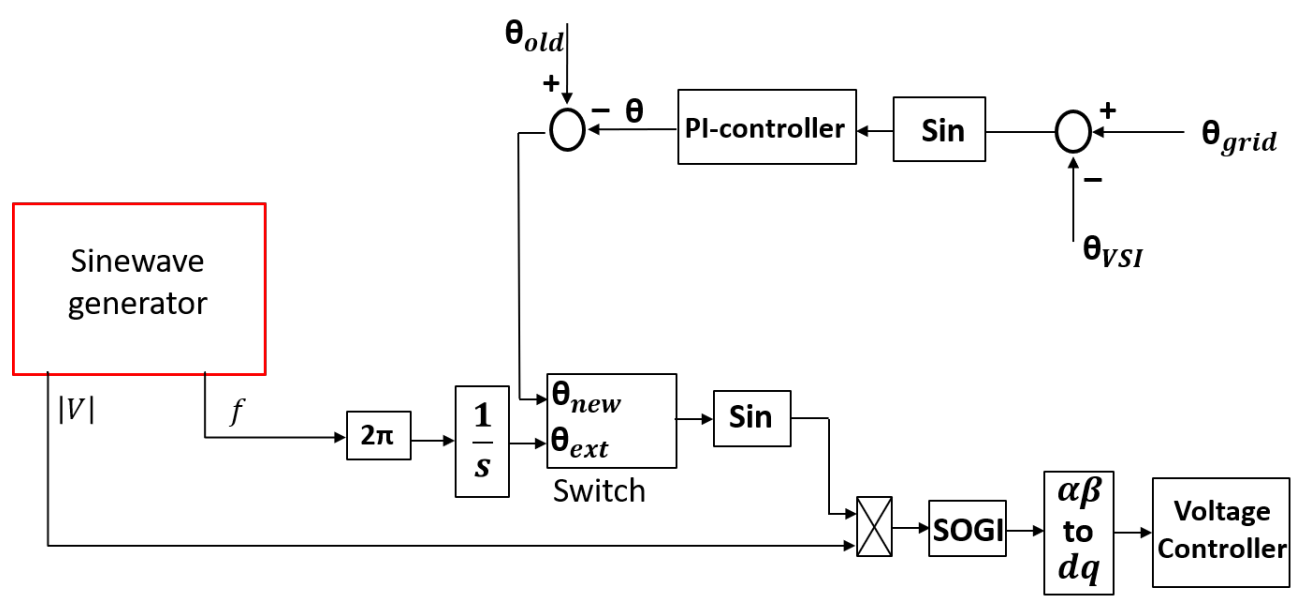

Figure 3. Synchronization controller structure

Figure 4 shows the proper coordination of flip flop 1 which represents the static switch, and flip flop 2 which represents the operation mode of the DG voltage source inverter. The protection scheme monitors the instantaneous grid current value. Then, the protection scheme output becomes high and subsequently the flip flops of the static switch, and the DG VSI operation mode are adjusted to the set command once the current overrides a specified or threshold value due to a short circuit occurrence in the main grid. Once the fault is cleared, the fault clear signal is set high manually to reset the flip flops. Therefore, the static switch is again reclosed and the operation mode of the VSI is changed to grid connected mode. The fault clear is triggered once the synchronization criterion derives the new phase angle during the islanded operation mode.

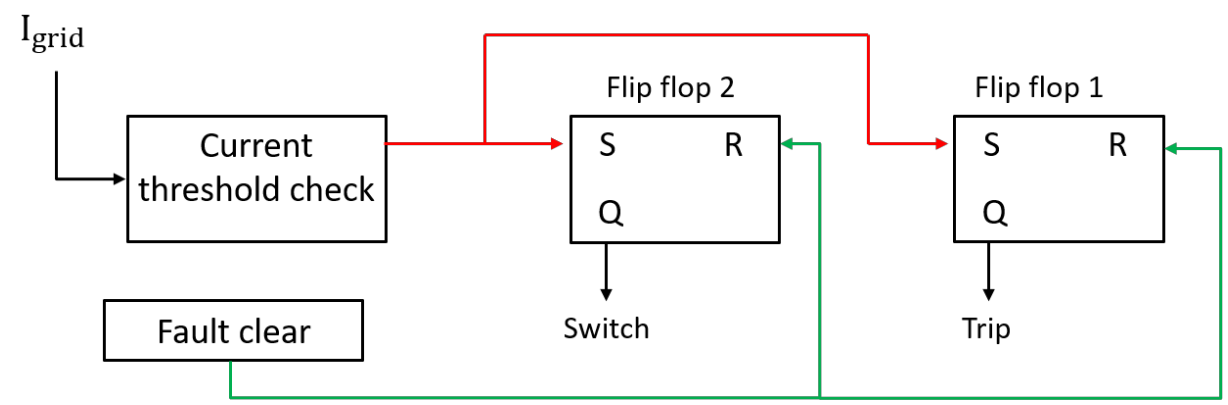

Figure 4. Coordination of the static switch, and operation mode of the DG VSI

\section{Simulation results}

The single-line diagram presented in Figure 1 is implemented as a simulation model by using Sim Power Systems toolbox in Simulink. The parameters of the utility grid and the microgrid are all presented in Table 1. A short circuit is proposed to occur at point B shown in Figure 1 where the short circuit begins at $\mathrm{t}=2 \mathrm{~s}$ and lasts for $300 \mathrm{~ms}$. The disconnection and reconnection of the DGs voltage source inverters are verified considering that the fault location is at point $\mathrm{B}$. 
Table 1. System Parameters

\begin{tabular}{|c|c|}
\hline System parameters & Values \\
\hline Grid & $230 \mathrm{~V} \mathrm{rms}$ \\
Grid voltage $\left(V_{g}\right)$ & $50 \mathrm{~Hz}$ \\
Grid Frequency $(\mathrm{f})$ & $0.0025 \Omega$ \\
Grid Resistance $\left(\mathrm{R}_{\mathrm{g}}\right)$ & $0.1 \mathrm{mH}$ \\
Grid Inductance $\left(\mathrm{L}_{\mathrm{g}}\right)$ & \\
\hline Microgrid VSIs & $0.1 \mathrm{mH}$ \\
VSI Inductance $\left(\mathrm{L}_{1,2}\right)$ & $0.5 \Omega$ \\
Line Resistance $\left(\mathrm{R}_{\text {line }}\right)$ & $1 \mathrm{mH}$ \\
Line Inductance $\left(\mathrm{L}_{\text {line }}\right)$ & $9.4 \mathrm{kVA}$ \\
VSI 1 rated power $(S)$ & $12.3 \mathrm{kVA}$ \\
VSI 2 rated power $(S)$ & \\
\hline
\end{tabular}

Figure 5 (a)-(c) depict the system behavior under short circuit condition without opening the static switch. It can be seen that the fault current has a transient peak of about $5 \mathrm{kA}$. The peak value of the PCC voltage is dropped to lower value and the rms voltage of both voltage source inverters (VSIs) is oscillating out of the acceptable limits. Thus, the microgrid VSIs should isolate themselves and switch to island control mode.

In this case, the fault is proposed to occur at the grid side and the total load demand is also considered as zero. The static switch will open and the microgrid VSIs will operate in island control mode. In island control mode, the microgrid VSIs frequency and phase angle will oscillate with a different value than the main grid. Before the fault clearance and reclosing of the static switch, the synchronization controller is triggered by the system operator to synchronize the microgrid VSIs with the main grid before the static switch is reconnected. Both VSIs are current controlled when they are operating in grid connected mode and voltage controlled when the microgrid is disconnected from the main grid. The system was initially operating in grid connected mode then the microgrid is disconnected at $\mathrm{t}=2 \mathrm{~s}$. Therefore, the control mode of both VSIs changed from current control (Grid-Connected) to voltage control (Island-Mode) operation. Figure 6 depict the voltage and current of both VSIs before and after the disconnection of the microgrid from the main grid. The voltage and current transient appeared at the moment of disconnection is due to the unintentional short circuit effect and the switching of the control mode from grid connected to islanded operation.

The microgrid is reconnected at $2.3 \mathrm{~s}$ to the main grid where a fault clear signal is triggered manually and sent to both flip flops to reset their states. Both DGs inside the microgrid were operating in island mode until their VSIs are synchronized with the main grid. The synchronization controller of both VSIs is triggered at $\mathrm{t}=2.2 \mathrm{~s}$ by the system operator. 
Qusay Salem, et al.

(a)

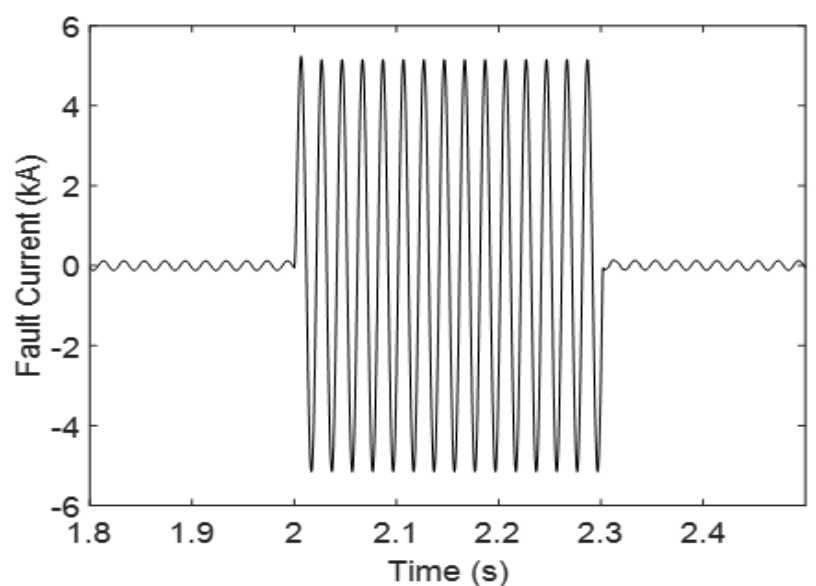

(b)

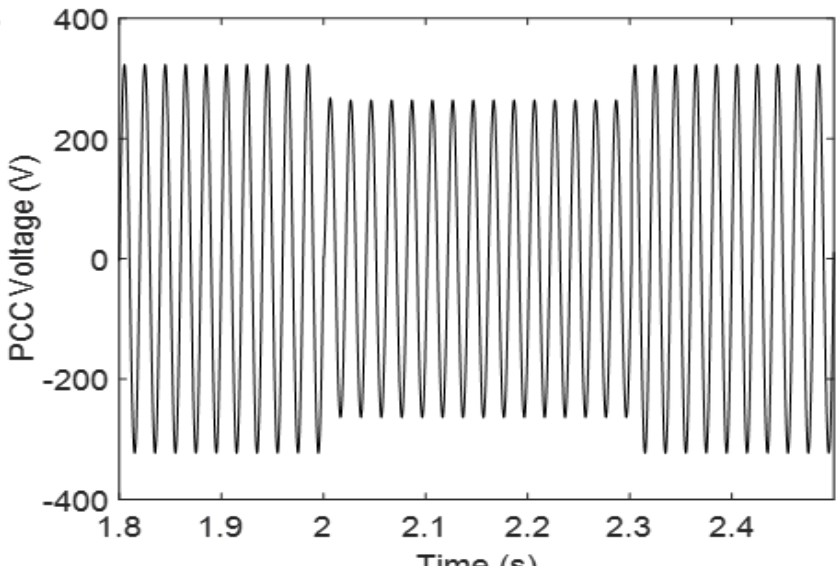

(c)

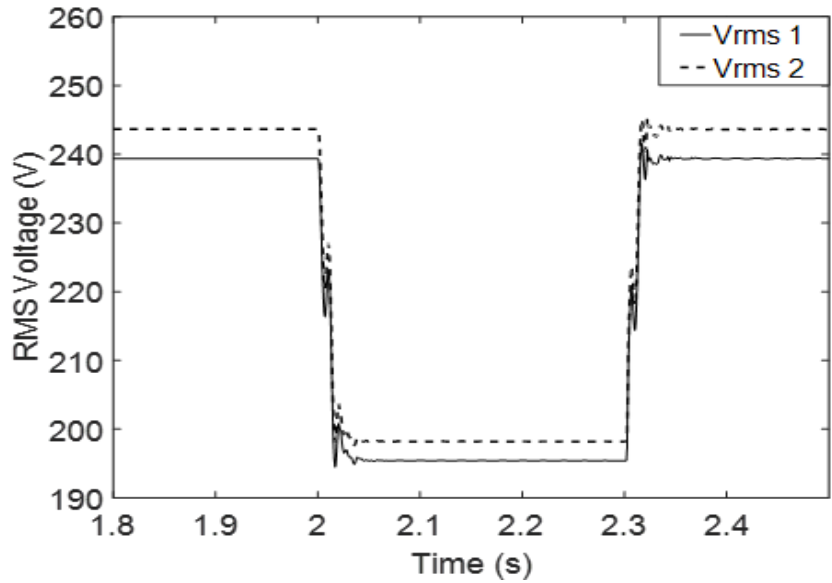

Figure 5. The system performance during a fault condition. (a) Fault current (b) PCC voltage (c) RMS voltage 
(a)

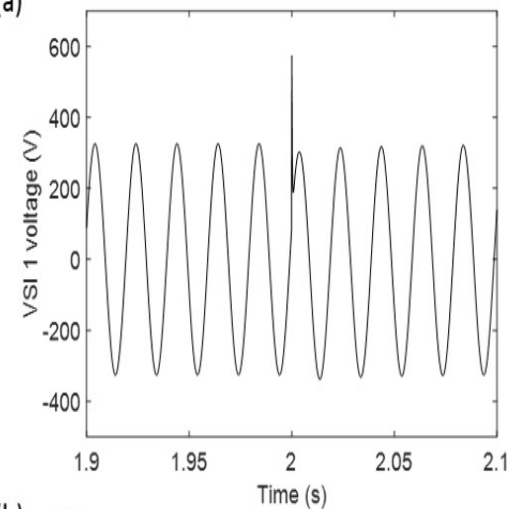

(b)

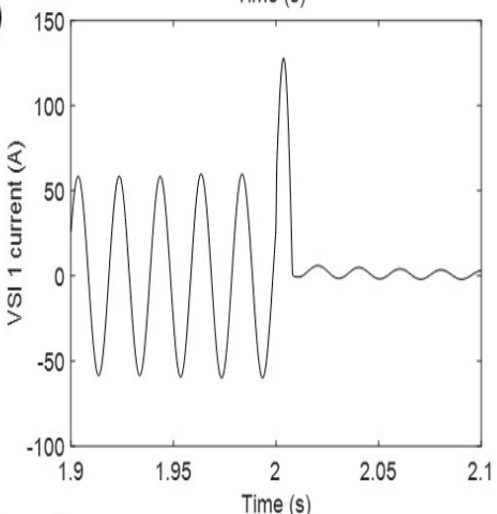

(c)

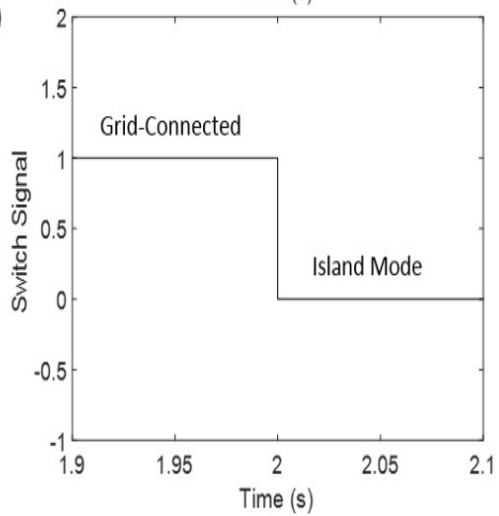

(d)

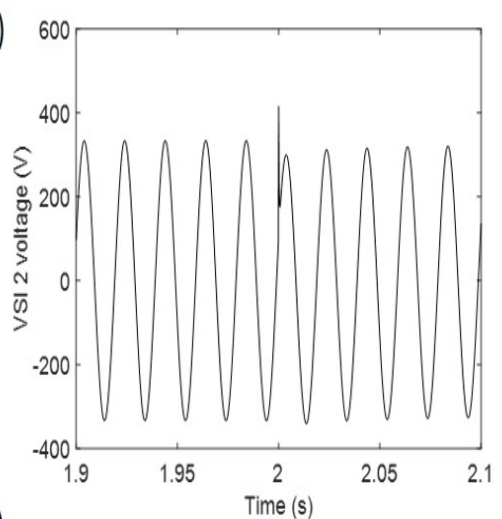

(e)

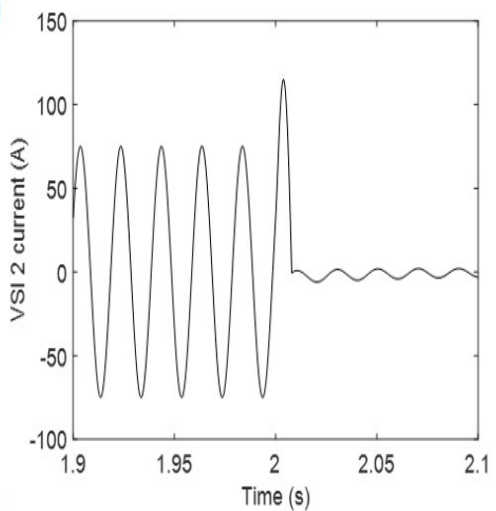

(f)

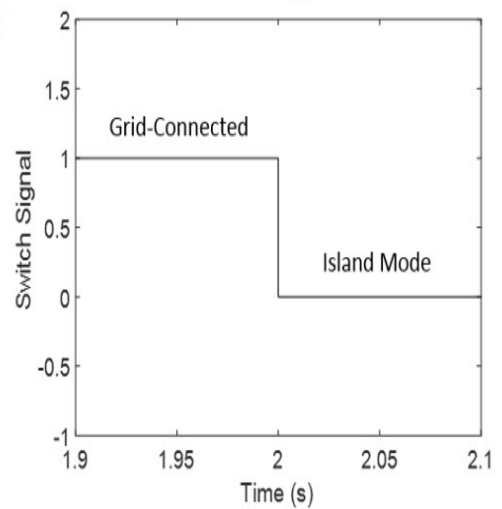

Figure 6. The performance of both DG voltage source inverters during the fault condition. (a) voltage of VSI 1 (b) current of VSI 1 (c) switch signal of VSI 1 (d) voltage of VSI 2 (e) current of VSI 2 (f) switch signal of VSI 2

Figure 7 demonstrates the detailed view of the reconnection of both VSIs voltage and phase angle with the main grid directly after the synchronization controller is triggered in the island mode. It is clearly shown that the proposed synchronization controller forces both VSIs voltage and phase angle to track the voltage and phase angle of the main grid. Once the reconnection process is completed, the DGs voltage source inverters are reconnected to the main grid and the control mode of both VSIs is changed from island mode to grid connected mode. It can be noted that the reconnection process of both VSIs is accomplished with free voltage transient and seamless transition from island mode to grid connected mode. 
(a)

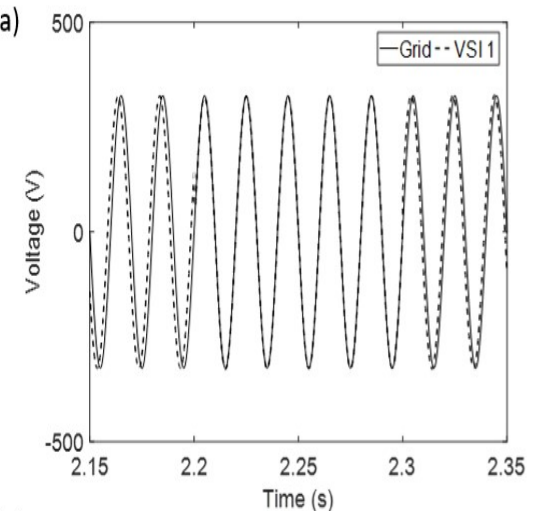

(b)

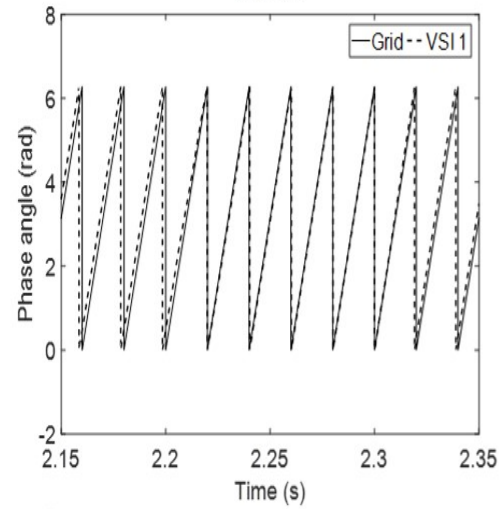

(c)

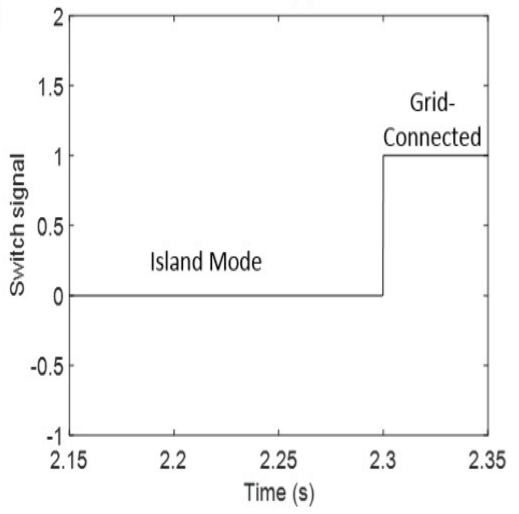

(d)

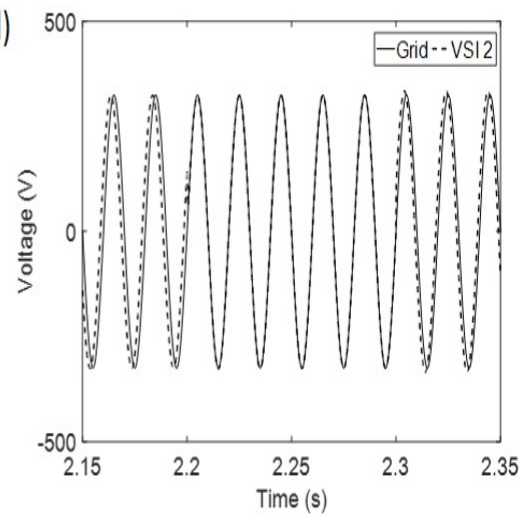

(e)

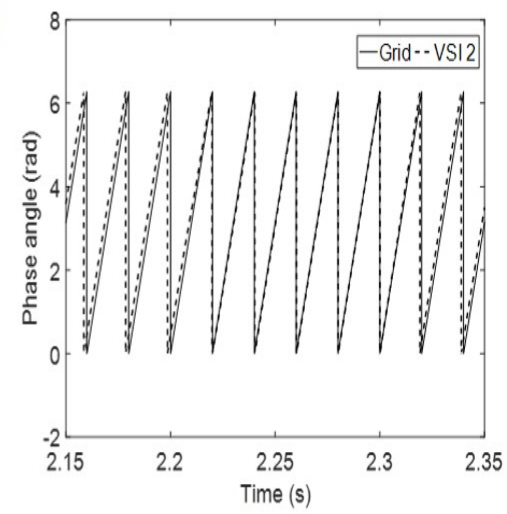

(f)

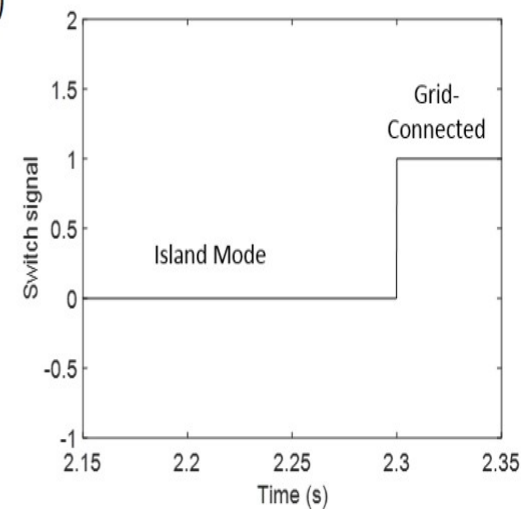

Figure 7. The performance of both DG voltage source inverters during reconnection process. (a) voltage of the grid and VSI 1 (b) phase angle of the grid and VSI 1 (c) switch signal of VSI 1 (d) voltage of the grid and VSI 2 (e) phase angle of the grid and VSI 2 (f) switch signal of VSI 2

Figure 8 shows a detailed view of the disconnection and reconnection process of the microgrid from the main grid in terms of the PCC voltage, current, real and reactive power. It is clearly shown that the voltage exhibits some transient at the moment of disconnection due to the unintentional short circuit effect. At the moment of reconnection, the transition between both modes exhibits free voltage transient. The PCC current shows some transient at the moment of disconnection and reconnection process. The current transient at the moment of disconnection is appeared due to the unintentional short circuit effect and it is worth noting that the current will cease to oscillate only at the next current zero crossing. At the moment of reconnection, the current transient is established due to the conflict of the transition from the voltage control mode 
to current control mode. The variation of active and reactive power at PCC when transferring from island mode to grid connected mode is reflected on the PCC current during reconnection. The active and reactive power at PCC, VSI 1, VSI 2 are also presented in the same figure. The system was operating initially in grid connected mode and both VSIs were injecting real and reactive power into the main grid. At $\mathrm{t}=2 \mathrm{~s}$, the microgrid is disconnected and operates in island mode. Since the load demand is zero, the active and reactive power exhibits zero value during the island mode. At $\mathrm{t}=2.3 \mathrm{~s}$, the microgrid is reconnected to the main grid. It is obvious that the active and reactive power exhibit fewer transient at the moment of disconnection and reconnection process. This transient is due to the conflict of the voltage controller and current controller of both operation modes when the transition occurred between both.

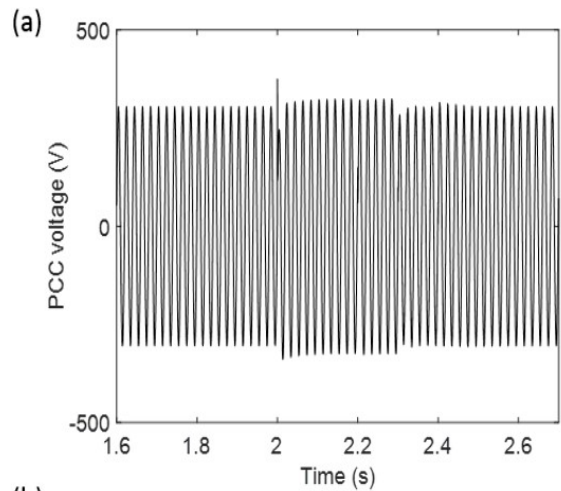

(b)

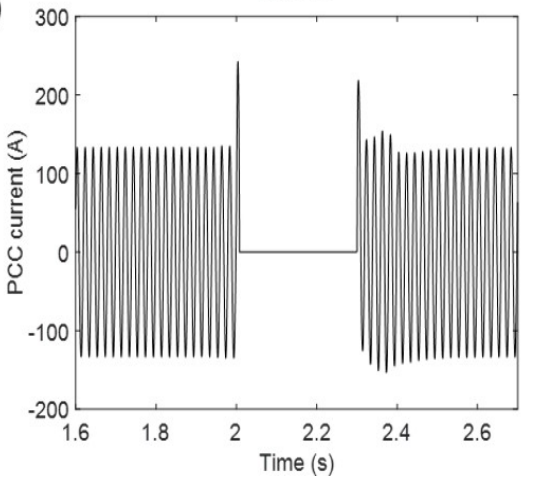

(c)

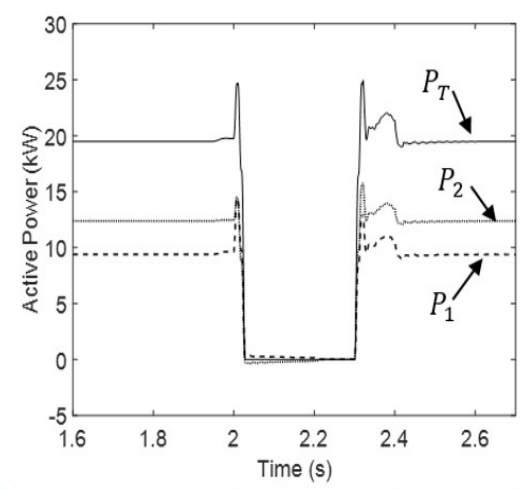

(d)

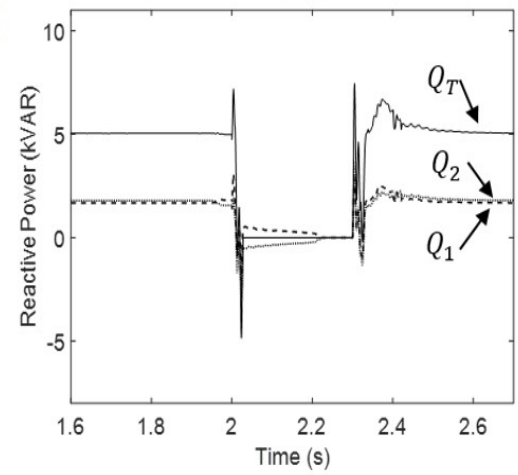

Figure 8. Complete view of the system parameters before and after the islanding event. (a) PCC voltage (b) PCC current (c) Active power of DG VSI 1, DG VSI 2, and PCC (d) Reactive power of DG VSI 1, DG VSI 2, and PCC

\section{Conclusion}

This paper investigates the performance of a synchronization controller installed within the control unit of each DG VSI inside the microgrid under a short circuit event. Disconnection and reconnection of the microgrid or the DG voltage source inverters have been validated through proper coordination of flip flops which manage the static switch and the operation mode of the DG VSI. The fault location is proposed to occur at the grid side. It was observed from the simulation results that the synchronization controller forces the DG voltage source inverters to track the voltage magnitude and phase angle of the main grid. Furthermore, it was noticed that the real and reactive power of the DG voltage source inverters have fewer transients at the disconnection and reconnection instants. These transients are due to the conflict between the current control in grid connected mode and voltage control in the islanded mode. This problem can be considered as a future work. 


\section{References}

[1]. T. Ghanbari and E. Farjah, "Unidirectional Fault Current Limiter: An Efficient Interface Between the Microgrid and Main Network," IEEE Transactions on Power Systems, vol. 28, no. 2, pp. $1591-1598,2013$.

[2]. T. Ghanbari and E. Farjah, "A Multiagent-Based Fault-Current Limiting Scheme for the Microgrids," IEEE Transactions on Power Delivery, vol. 29, no. 2, pp. 525 - 533, 2014.

[3]. Q. Salem and J. Xie, "Decentralized power control management with series transformerless H-bridge inverter in low-voltage smart microgrid based P/V droop control," International Journal of Electrical Power \& Energy Systems, vol. 99, pp. 500-515, 2018.

[4]. H. Lala, S. Karmakar and S. Ganguly, "Fault Detection and Localization using Continuous Wavelet Transform and Artificial Neural Network Based Approach in Distribution System," International Journal of Electrical Engineering and Informatics, vol. 10, no. 2, pp. 203-219, 2018.

[5]. Q. Salem and K. Alzaareer, "Detailed analysis of grid connected and islanded operation modes based on $\mathrm{P} / \mathrm{U}$ and $\mathrm{Q} / \mathrm{f}$ droop characteristics," International Journal of Power Electronics and Drive Systems, vol. 12, no. 2, pp. 772-782, 2021.

[6]. C. PAPADIMITRIOU, V. KLEFTAKIS and N. HATZIARGYRIOU, "Control strategy for seamless transition from islanded to interconnected operation mode of microgrids," Journal of Modern Power Systems and Clean Energy, vol. 5, p. 169-176, 2017.

[7]. B. N. Alhasnawi and B. H. Jasim, "A Novel Hierarchical Energy Management System Based on Optimization for Multi-Microgrid," International Journal of Electrical Engineering and Informatics, vol. 12, no. 3, pp. 586-606, 2020.

[8]. L. Tao, C. Schwaegerl, S. Narayanan and J. H. Zhang, "From laboratory Microgrid to real markets-challenges and opportunities," in 8th International Conference on Power Electronics - ECCE Asia, Jeju, 2011.

[9]. H. Laaksonen and K. Kauhaniemi, "Stability of Microgrid with Different Configurations after Islanding Due to Fault in the Utility Grid," International Review of Electrical Engineering, vol. 3, no. 3, pp. 498-512, 2008.

[10]. I. J. Balaguer, S. Y. Q. Lei, U. Supatti and F. Z. Peng, "Control for grid-connected and intentional islanding operations of distributed power Generation," IEEE Transactions on Industrial Electronics, vol. 85, no. 1, pp. 147-157, 2011.

[11]. Q. Salem and K. Alzaareer, "Fault Ride-Through Capability with Mutual Inductance in Low-Voltage Single-Phase Microgrid," IETE Journal of Research, 2020.

[12]. Lei Chen et al., "Application of a modified flux-coupling type superconducting fault current limiter to transient performance enhancement of micro-grid," Physica C, vol. 518, p. 144 $148,2015$.

[13]. Huiwen He et al., "Application of a SFCL for Fault Ride-Through Capability Enhancement of DG in a Microgrid System and Relay Protection Coordination," IEEE Transactions on Applied Superconductivity, vol. 26, pp. 1-8, 2016.

[14]. Lei Chen et al., "Technical Evaluation of Superconducting Fault Current Limiters Used in a Micro-Grid by Considering the Fault Characteristics of Distributed Generation, Energy Storage and Power Loads," Energies, vol. 9, no. 10, 2016.

[15]. G. Spyros and D. Charis, "A control strategy for enhancing the Fault Ride-Through capability of a microgrid during balanced and unbalanced grid voltage sags," Sustainable Energy, Grids and Networks, vol. 3, p. 1-11, 2015.

[16]. Q. Salem, L. Liu and J. Xie, "Dual operation mode of a transformerless H-bridge inverter in low-voltage microgrid," IEEE Transactions on Industry Applications, vol. 55, no. 5, pp. 5289-5299, 2019.

[17]. Q. Salem, L. Liu and J. Xie, "Islanding and resynchronization process of a grid-connected microgrid with series transformerless H-bridge inverter installed at PCC," in 2018 IEEE International Conference on Environment and Electrical Engineering and 2018 IEEE Industrial and Commercial Power Systems Europe (EEEIC/I\&CPS Europe), Palermo, 2018 . 
[18]. T. Thacker, F. Wang and D. Boroyevich, "Islanding Control of a Distributed Generation Unit's Power Conversion System to the Electric Utility Grid," in IEEE 36th Power Electronics Specialists Conference, Dresden, 2006.

[19]. H. Kim, T. Yu and S. Choi, "Indirect Current Control Algorithm for Utility Interactive Inverters in Distributed Generation Systems," IEEE Transactions on Power Electronics, vol. 23, no. 3, pp. 1342 - 1347, 2008.

[20]. J. M. Guerrero, N. Berbel, J. Matas, J. L. Sosa and L. G. d. Vicuna, "Control of LineInteractive UPS Connected in Parallel Forming a Microgrid," in IEEE International Symposium on Industrial Electronics, Vigo, 2007.

[21]. R. Teodorescu and F. Blaabjerg, "Flexible control of small wind turbines with grid failure detection operating in stand-alone and grid-connected mode," IEEE Transactions on Power Electronics, vol. 19, no. 5, pp. 1323 - 1332, 2004.

[22]. Y. Li, D. M. Vilathgamuwa and P. C. Loh, "Design, analysis, and real-time testing of a controller for multibus microgrid system," IEEE Transactions on Power Electronics, vol. 19, no. 5, pp. 1195-1204, 2004.

[23]. J. C. Vasquez, J. M. Guerrero, A. Luna, P. Rodriguez and R. Teodorescu, “Adaptive Droop Control Applied to Voltage-Source Inverters Operating in Grid-Connected and Islanded Modes," IEEE Transactions on Industrial Electronics, vol. 56, no. 10, pp. 4088 - 4096, 2009.

[24]. C. Cho, J.-H. Jeon, J.-Y. Kim, S. Kwon, K. Park and S. Kim, “Active Synchronizing Control of a Microgrid," IEEE Transactions on Power Electronics, vol. 26, no. 12, pp. 3707 - 3719, 2011.

[25]. J. Rocabert, G. M. S. Azevedo, A. Luna, J. M. Guerrero, J. I. Candela and P. Rodríguez, "Intelligent Connection Agent for Three-Phase Grid-Connected Microgrids," IEEE Transactions on Power Electronics, vol. 26, no. 10, pp. 2993 - 3005, 2011.

[26]. C. Jin, M. Gao, X. Lv and M. Chen, "A seamless transfer strategy of islanded and gridconnected mode switching for microgrid based on droop control," in IEEE Energy Conversion Congress and Exposition (ECCE), Raleigh, 2012.

[27]. Q. Salem and J. Xie, "Transition from grid-connected to islanded drooped microgrid based on islanding detection scheme," International Journal of Power and Energy Systems, vol. 36, no. 3, 2016.

[28]. Q. Salem and J. Xie, "Active power control using an alternative series connection scheme between the utility grid and Microgrid," in 2016 IEEE 16th International Conference on Environment and Electrical Engineering, Florence, 2016.

[29]. Y. Li, D. M. Vilathgamuwa and P. C. Loh, "Design, Analysis, and Real-Time Testing of a Controller for Multibus Microgrid System," International Journal of Power Electronics, vol. 19, no. 5, pp. 1195-1204, 2004.

[30]. Z. Yao, L. Xiao and Y. Yan, "Seamless Transfer of Single-Phase Grid-Interactive Inverters Between Grid-Connected and Stand-Alone Modes," International Journal of Power Electronics, vol. 25, no. 6, pp. 1597-1603, 2010. 


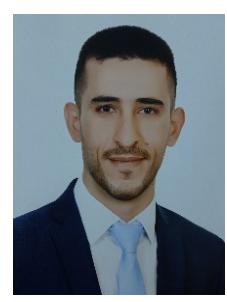

Qusay Salem has been awarded the $\mathrm{PhD}$ degree in Electrical Power and Energy Engineering from University of Ulm - Germany, in 2020. He received the B.Sc. and M.Sc. Degree both in Electrical Power Engineering from University of Mutah and Yarmouk University - Jordan, in 2009 and 2013, respectively. Currently, he serves as an Assistant Professor with the Department of Electrical Engineering at Princess Sumaya University for Technology. His research interests include power control and energy management in low-voltage smart microgrids, Islanding detection schemes, Series power flow controllers.

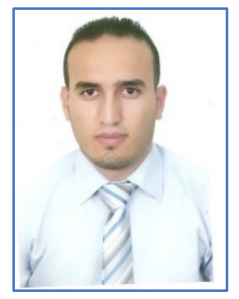

Khaled Alzaareer received the PhD degree in Electrical Engineering/ Power Systems from Quebec University (ETS), Montreal, QC, Canada in Dec. 2020. $\mathrm{He}$ also received the bachelor's and master's degrees in electrical power engineering from Yarmouk University, Irbid, Jordan, in 2010 and 2012, respectively. His research interests are smart grid, sensitivity analysis, renewable energy integration, voltage stability and control.

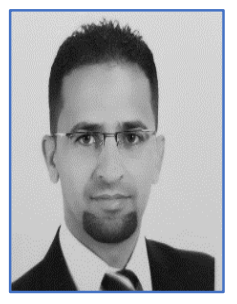

Salman Harasis received the B.Sc. degree in electrical power engineering from Tafila Technical University, Tafila, Jordan, in 2009. Received the M.Sc. degree in electrical engineering from Polytechnic University of Bucharest, Bucharest, Romania, in 2013. Received the Ph.D. degree in electrical engineering from the University of Akron, OH, USA in 2020. He is currently an Assistant Professor with the Department of Electric power and Mechatronics engineering, Tafila Technical University. His research interests include control of power systems and microgrids, renewable energy, power electronics, and motor drives for transportation electrification applications. 